\title{
A ESCRITA DE CLIO NOS TEMP(L)OS DA MNEMÓSIME: OLHARES SOBRE MATERIAIS PEDAGÓGICOS PRODUZIDOS PELOS MUSEUS
}

\author{
Carina Martins Costa*
}

RESUMO: O artigo pretende abordar os desafios e as potencialidades do ensino de História nos museus, em um cenário de predomínio da memória como referência para narrativas e lutas políticas. Os materiais pedagógicos produzidos pelos museus serão um ponto de partida para perceber concepções de história, memória e aprendizagem instrumentalizadas pelos museus históricos com o objetivo de educar. O museu, concebido como espaço de poder, é produtor de sentidos do passado e, portanto, suas múltiplas linguagens fomentam acessos para a compreensão de permanências e rupturas dos projetos de História nacional. Neste sentido, a importância da preservação das fontes pedagógicas é realçada, como proposta para a construção de interpretações sobre a educação museal no Brasil.

Palavras-chave: educação em museus, ensino de História, materiais pedagógicos

\section{CLIO IN TIME AND AT THE SHRINE OF MNEMOSYNE: A VIEW ON PEDAGOGICAL MATERIALS IN HISTORICAL MUSEUMS}

ABSTRACT: This article analyzes the challenges and the potential of teaching history in museums, a scenario in which memory predominates as a reference for narratives and political confrontation. In the face of the growing demand of memory, museums are meaningful spaces of production and diffusion of the discourse on the past. Historical museums, regarded as spaces of power, afford pedagogical materials as starting points for the perception of the concepts of history, memory, and learning and lend meaning to the past. Their multiple languages lead to the understanding of the continuity and the discontinuity of the national history projects. The importance of preserving pedagogical sources is highlighted within the framework of museum education in Brazil. Keywords: Museum Education; History Teaching; Pedagogical Materials

\footnotetext{
* Doutoranda em História, Política e Bens Culturais na Fundação Getúlio Vargas (CPDOC/FGV). Fundação Museu Mariano Procópio (Departamento de Difusão Cultural).E-mail: mardilha@terra.com.br
} 


\section{INTRODUÇÃO}

Interessantes diagnósticos já foram traçados sobre a "pós-modernidade", a "sociedade do consumo" ou o "capitalismo avançado". Instituições modernas geralmente vinculadas a processos de reprodução social, como escolas e museus, são questionadas tanto pelo que são quanto pelo que veiculam. Ao mesmo tempo, estudiosos apontam sobre o poder da ressignificação e da apropriação do discurso pelos leitores, ressaltando o potencial criativo e transformador de espaços considerados tradicionais.

O processo de questionamento das instituições, porém, manifestase em um cenário de complexo rearranjo econômico mundial, em que é delegado ao capital o papel de quociente comum entre diferentes povos, culturas e países. Esse processo vem se defrontando com a eclosão de variados conflitos étnicos, em que a questão da diversidade se impõe objetivamente no cenário político e reacende debates sobre a convivência com o outro.

A agenda pública pleiteada pela sociedade civil enfoca, de forma cada vez mais contundente, a luta pelo reconhecimento e pelo espaço de diversas memórias. Assim, a noção de "museu", assim como seus valores e narrativas, é questionada em prol de uma maior pluralidade e maior democratização.

Paralela a essa reflexão, há a constatação de que o final do século XX e o início do XXI marcam a explosão das demandas pela memória, que teria sido apropriada pelo mercado e, portanto, pela lógica do reciclável e do efêmero. Andreas Huyssen (2000), ao tentar traçar um mapa para o cenário atual, reflete sobre a crise da experiência moderna do tempo, que enseja a procura de ancoragem temporal por indivíduos e grupos, tendo em vista que o tripé território/nação/ tempo linear não representa mais fronteiras seguras.

Jesus-Barbero (1999) questiona o que denomina de tempo "autista", auto-referenciado, que transforma o passado em pastiche e o futuro em repetição. De acordo com o autor, essa noção de passado não permite operar com distanciamento em relação ao vivido e "(...) sólo contribuye a hundirnos en un presente sin fondo, sin piso y sin horizonte" (BARBERO, 1999, p. 37).

Nesse cenário, os museus históricos repensam suas narrativas e seus projetos educativos que, mesmo nas entrelinhas, vêm colaborando decisivamente na formação de projetos de cidadania e nação. Todavia, ironicamente, negligenciam os fios de sua própria memória, obstaculizando a possibilidade de perceber a construção de suas tramas históricas. 
O trabalho proposto pretende perceber alguns desses fios, por meio de textos pedagógicos, no sentido de resgatar fontes importantes para a compreensão do discurso museológico brasileiro.

\section{A ESCRITA DA HISTÓRIA DOS MUSEUS}

Os museus têm assumido lugar de destaque nos debates que envolvem a problematização das relações com o presente e com o passado. Mais do que nunca, questiona-se o tradicional entendimento de que as narrativas construídas com os objetos históricos são expressões naturais de um passado nacional uniforme e essencializado. Por outro lado, aprofunda-se a idéia de que o discurso museológico é produto de uma seleção feita com objetivos políticos e estéticos específicos (PIO, 2006).

Tradicionalmente, os museus, como lugares de memória e esquecimento, forjaram projetos educativos para os cidadãos, quaisquer que sejam as definições de educação e/ou cidadania. Os museus da modernidade foram marcados pelo caráter disciplinador, explícito na organização do tempo e dos espaços, na vigilância do patrimônio e na sacralização de objetos e culturas. Os principais objetivos dessas instituições seriam educar o indivíduo, estimular seu senso estético e afirmar o nacional (CHAGAS, 2001).

Como instrumentos pedagógicos, os museus desempenham importante papel no que diz respeito não só à criação de consciências pessoais, mas também à construção e à representação de identidades coletivas diversas. Como terrenos contestados, têm sido alvo de profundas revisões no que diz respeito à natureza de suas coleções, às modalidades de representação cultural e ao papel dos visitantes. Em suma, a própria identidade e a missão de tais instituições passam por um momento de intensos estudos, revisões e debates (ANICO, 2005).

Contudo, os museus históricos ${ }^{1}$ mostram-se, em geral, impermeáveis aos questionamentos sobre os usos e abusos do passado, reforçando narrativas cronológicas, pautadas em esquecimentos deliberados sobre períodos de conflito e ruptura. Um olhar panorâmico permite-nos apontar forte tendência de teatralização do passado nacional, mecanismo pelo qual todo o processo museográfico é silenciado e, aos olhos do visitante, torna-se possível voltar ao tempo. Porém, a tendência monologizante da enunciação do discurso não implica silenciamentos cognitivos, visto que diferentes estratégias de leitura são lançadas pelos sujeitos no processo de ressignificação do mesmo.

Importantes trabalhos (ABREU, 1996; BREFE, 2005; SANTOS, 2006) têm apontado as estratégias de construção de uma interpre- 
tação da História e do Brasil por meio da pesquisa documental sobre as coleções, a história institucional e os discursos museográficos. Da mesma forma, as pesquisas relativas à educação não-formal nesses espaços crescem em número e qualidade. A produção concentra-se, em larga medida, em análises de processos comunicativos, estudos quantitativos de público e descrições de atividades pedagógicas.

O trabalho proposto pretende abordar fontes pouco exploradas para a compreensão dos processos de ensino de História nos museus, os materiais pedagógicos. É preciso destacar a dificuldade em acessar os materiais não publicados em formato de livros, almanaques e cartilhas. Muitos não são preservados pelas instituições museais, que têm atuado de forma negligente na preservação de sua memória. É necessário um árduo trabalho de mapeamento dessas fontes, tanto nas instituições quanto nas escolas.

Em contrapartida, a pesquisa intitulada "Educação Patrimonial" (FJP/2001), realizada pela Fundação João Pinheiro, em Minas Gerais, reuniu cerca de 250 professores da rede estadual de ensino e demonstrou que a grande maioria $(86,1 \%)$ manifestou interesse em relação aos materiais pedagógicos produzidos por museus. Os educadores apontaram a necessidade de materiais de suporte para o fazer educativo, tanto para professores quanto para alunos. Esses dados indicam a existência de demandas concretas por materiais pedagógicos produzidos pelos ou a partir dos museus.

Em uma sondagem em sites de museus brasileiros e internacionais, há poucas referências a materiais pedagógicos. Observa-se o predomínio de atividades lúdicas e informativas, descomprometidas com o desenvolvimento de habilidades formativas a partir do acervo e de sua historicidade ${ }^{2}$.

A dissertação de Vera de Alencar (1987) possibilitou o acesso a alguns materiais educativos da década de 1980. Ao que tudo indica, havia o predomínio das fichas didáticas, elaboradas pelos setores educativos na tentativa de didatizar a exposição, em formato de fácil reprodutibilidade, possivelmente mimeografadas. A maior parte delas era ilustrada, mas as imagens eram apenas enfeites, pois não eram sequer problematizadas. As perguntas eram predominantemente factuais e conceituais, do tipo "A qual dinastia pertencia D. Pedro I?”. Outra ficha solicitava à criança o preenchimento da fachada de um museu, que, por sua simetria, reduzia a atividade à cópia. À criança, pensada como aluno, restava apenas copiar.

A partir dos anos 1990, é possível perceber a sofisticação dos produtos pedagógicos dos museus. Os materiais passam a ser produzidos 
em formatos mais duradouros, com papel de melhor qualidade e em policromia. Há esforço de criar situações de diálogo com o leitor e diminuir o uso de termos ou informações estritamente técnicos.

Contudo, uma importante questão precisa ser analisada: cada vez mais, esses produtos são transformados em mercadorias disponíveis nas lojas dos museus. Conforme analisa Huyssen (2000, p. 24), “o passado está vendendo mais do que o futuro", o que implica a constituição de um mercado de comercialização de memórias. No Brasil, essa questão se agrava com o cenário de pauperização da maioria dos museus, que encontra na venda de ingressos e produtos um importante mecanismo de geração de renda.

É necessário investigar, ainda, o uso desses materiais, enfatizando as múltiplas possibilidades de sua apropriação pelo leitor. Dessa forma, o poder do texto como transmissor de ideologias e visões de mundo é relativizado pelas mediações ocorridas nos processos de leitura. Essa reflexão é importante e alerta para o risco de compreensão da comunicação como um processo definido apenas pelo emissor. Porém, apesar de tal preocupação estar nos horizontes reflexivos do presente trabalho, não será aqui abordada.

Alguns materiais foram selecionados para a leitura compartilhada, procurando perceber marcas do diálogo projetado pelo autor para seu auditório social. É necessário um esforço para a compreensão dos textos em seus contextos históricos, marcados por concepções de ensinoaprendizagem, de história, de memória e de museu. Por outro lado, diante da variação de suportes dos materiais produzidos ${ }^{3}$, foram selecionados, para este artigo, os impressos.

É importante salientar que o museu educa por meio da tridimensionalidade e, nesse sentido, a exposição e todas as linguagens que a compõem educam não somente o olhar, mas também sobre a História. Porém, a intenção foi perceber a construção de materiais produzidos com fins pedagógicos destinados aos educandos ${ }^{4}$.

Antônio Augusto Batista (2002), ao pensar uma análise dos livros didáticos brasileiros, propõe o conceito de contratos de leitura, que seria uma forma de pensar o modo pelos quais esses diferentes materiais encenam sua leitura e seu uso. Segundo o autor,

(...) há uma diversidade acentuada nos "contratos" propostos e eles ensejam diferentes modos de estruturação e organização do material didático, assim como diferentes modos de articulação com o trabalho pedagógico e os processos de ensino e formação (BATISTA, 2002, p.544). 
Essa proposta converge com o pensamento do filósofo russo Mikhail Bakhtin, pois, para ele, cultura é um universo semiótico de interações vasto e complexo (FARACO, 1996, p. 118). Além disso, o homem é compreendido como ser de linguagem, constituído na e pela interação. Compreende-se, assim, o papel preponderante que Bakhtin advoga para a linguagem, condição para a possibilidade das relações sociais. Os sujeitos em interação gerariam diálogos, cuja dimensão epistemológica não pode ser depreendida do sentido formal. Bakhtin defende um sentido mais amplo, pois, segundo ele, “(...) toda comunicação verbal, de qualquer tipo que seja” é um diálogo (apud FARACO, 1996, p. 124). E, como os sujeitos interacionais são concretos e históricos, a alteridade é uma dimensão estrutural do diálogo: “(...) os outros constituem dialogicamente o eu que se transforma dialogicamente num outro de novos eus" (apud FARACO, 1996, p. 125).

É importante destacar aqui a importância das avaliações sociais, sugeridas por Bakhtin, como as organizadoras da forma. Segundo ele, "julgamentos de valor, antes de tudo, determinam a seleção das palavras do autor e a recepção desta seleção (a co-seleção) pelo ouvinte" (VOLOSHINOV, BAKHTIN, 1926, p. 12).

Assim, seria possível analisar a seleção e os presumidos da autoria, mesmo que deslocados de sua recepção, igualmente responsiva. Esse é um dos desafios na análise da produção de materiais pedagógicos de museus.

\subsection{A encenação do passado}

O Museu Imperial (Petrópolis, RJ) atua como um paradigma para o público sobre a possibilidade de acessar o passado pela encenação. Assim, a análise de alguns textos pedagógicos produzidos pela equipe do MI pode indicar marcas deste discurso. A seguir, uma ficha didática produzida na década de $1980^{5}$, produzida em formato de fácil reprodutibilidade. 
Meu nome é:

Visitei o Palácio Imperial em:

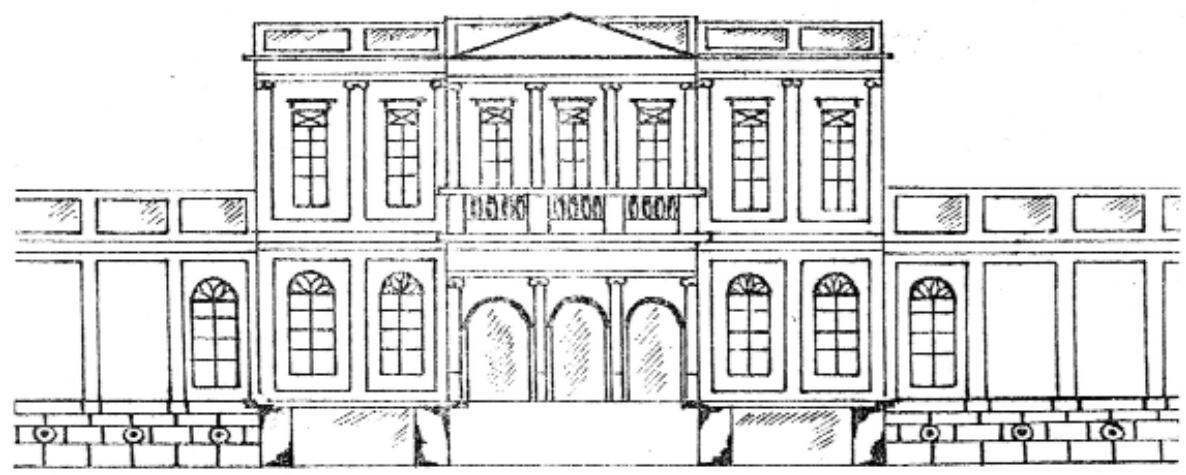

O que está faltando no desenho? Complete.

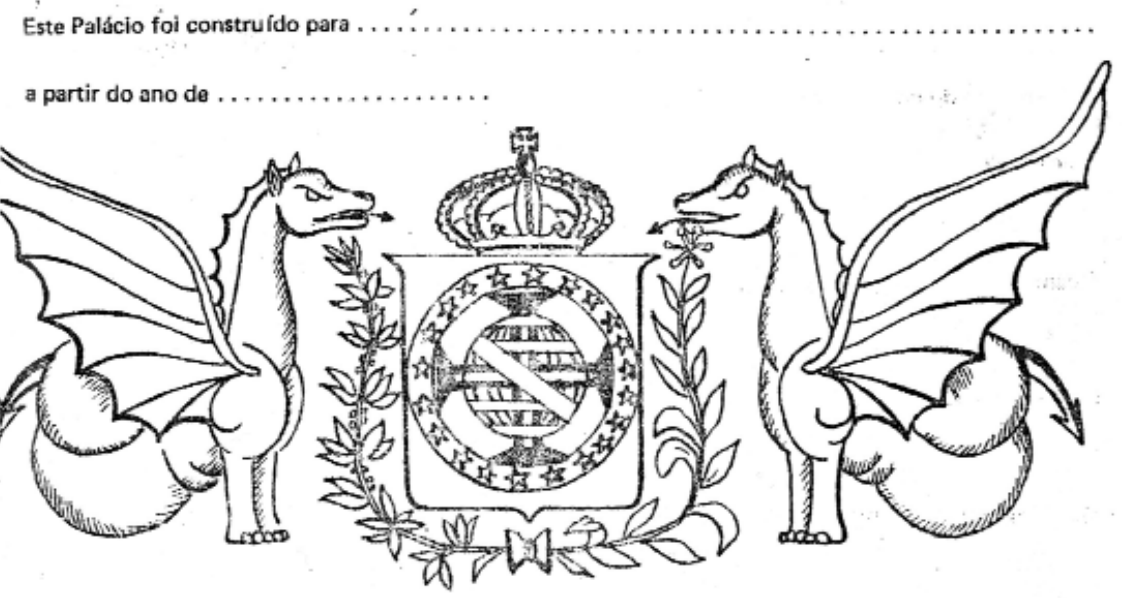

Estas são as armas da famnlia

Os diragões são o símbolo da casa de Bragança.

IMAGEM 1

A ficha deveria ser preenchida pela criança, o que é perceptível pelos espaços pontilhados. Em primeiro lugar, anota-se o nome e a data de visita ao museu. A primeira atividade é completar o desenho da fachada do prédio. Devido à simetria do conjunto, resta à criança apenas 
copiar as janelas nos espaços em branco. As habilidades são as de observação e cópia.

A questão seguinte leva a completar uma frase com informações factuais, possivelmente transmitidas ao longo da visita. A habilidade é a de memorização. O desenho dos símbolos imperiais é seguido por outra atividade - a de completar o nome da família. Uma das respostas possíveis está na próxima frase.

Assim, as marcas da concepção objetivista de aprendizagem estão explícitas. O caráter lúdico esconde a força do discurso monologizante que, de acordo com Bakhtin, reforça apenas a voz do autor. À criança, resta apenas copiar.

É importante apontar que o Museu Imperial, nos anos 1980, assumiu para si o pioneirismo da aplicação da 'educação patrimonial' no Brasil ${ }^{6}$. Um marco importante foi a realização do $1^{\circ}$ Seminário de Educação Patrimonial, em 1983.

A partir desse momento, a diretora da instituição, Maria de Lourdes Horta, desempenhou importante papel na divulgação dos pressupostos da metodologia, como no trabalho referencial em que a educação patrimonial foi definida como "um processo permanente e sistemático de trabalho educacional, centrado no Patrimônio Cultural como fonte primária de conhecimento e enriquecimento individual e coletivo" (HORTA; GRUNBERG; MONTEIRO, 1999, p. 6).

A metodologia proposta organiza-se a partir do objeto cultural e procura desvendar o complexo sistema de relações contido nele, por meio de atividades de observação, registro, exploração e apropriação. Dessa forma, propicia-se o desenvolvimento de habilidades e conceitos a partir de fases sucessivas de interrogação ao objeto.

Nessa perspectiva, o visitante não é percebido apenas como espectador do discurso construído, pois seriam proporcionados espaços de interlocução nos quais múltiplas leituras sobre os objetos culturais seriam estimuladas, com o objetivo de desenvolver o potencial crítico e a apropriação consciente do patrimônio. Nas palavras das autoras (HORTA; GRUNBERG; MONTEIRO, 1999, p. 6, grifos originais),

a Educação Patrimonial é um instrumento de "alfabetização cultural" que possibilita ao indivíduo fazer a leitura do mundo que o rodeia, levando-o à compreensão do universo sociocultural e da trajetória histórico-temporal em que está inserido. Este processo leva ao reforço da auto-estima dos indivíduos e comunidades e à valorização da cultura brasileira, compreendida como múltipla e plural. 
O descompasso entre a metodologia e a ficha reproduzida pode demonstrar, entre vários fatores, a dificuldade em romper não apenas com os métodos de ensino, mas, sobretudo, com uma concepção de História que privilegia a informação e o fato em detrimento das habilidades e dos contextos.

Ainda nos anos 1990, o Museu Imperial (MI) editou dois livros destinados ao público infantil. Em ambas as produções, a linguagem é acessível e as são informações organizadas sob a forma narrativa. Conforme Faraco assinala, o ato estético “(...) opera sobre sistemas de valores e cria novos sistemas de valores. (...) Envolve um complexo processo de transposições refratadas da vida para a arte (...) a partir de um certo viés valorativo" (FARACO, 2005, p.39). Assim, as duas obras publicadas pelo MI trazem concepções de história, da importância dos personagens e do próprio leitor.

A primeira obra, Uma princesa de fibra..., foi escrita por Maria de Lourdes Horta (1997) e ilustrada por Pedro Mazzillo Costa. O livro foi produzido com o objetivo de acompanhar a exposição do bicentenário do nascimento da imperatriz D. Leopoldina. Nas palavras da autora,

transformar a História em "estória", fiel aos fatos e acontecimentos, mas recuperando o sentido da aventura humana, do maravilhoso que pode existir na própria vida, do fantástico que se esconde atrás dos relatos frios e pretensamente objetivos do ensino tradicional, é uma maneira possível de abrir os olhos do espírito e da sensibilidade da criança, permitindo-lhe que se aproprie de uma trajetória que lhe pertence, e na qual ela se insere como personagem vivo e presente. (HORTA, 1997, contracapa).

O texto narrativo centra-se em detalhes da vida de D. Leopoldina, apresentada como inteligente e defensora do Brasil, apesar de estrangeira. Ao longo de doze páginas, duas interlocuções são abertas ao leitor, ambas de caráter factual, baseadas em conhecimentos prévios: "Você sabe como ela se chamava e onde ela nasceu?" (HORTA, 1997, p. 1) e "Era o dia 7 de setembro de 1822 . Você sabe o que aconteceu então?" (HORTA, 1997, p. 13).

A preocupação com a 'fidelidade aos fatos e acontecimentos' é evidenciada na centralidade de datas e nomes ao longo do texto. As fontes complementares servem como ilustração à narrativa, mesmo no caso das duas pinturas históricas reproduzidas ${ }^{7}$, que são apresentadas sem legenda.

O texto termina em tom elogioso e convoca o leitor a engrossar o grupo de admiradores da Princesa Leopoldina: “(...) por sua coragem e firmeza, e seu amor por nossa pátria, devemos a esta princesa um grande 
respeito e admiração" (p. 18). Na ilustração da última página, Leopoldina aparece como uma miragem entre as nuvens, sendo aclamada por uma multidão, na qual se destacam, em primeiro plano, as imagens de um índio, um branco e um negro. A democracia racial sorri para o estrangeiro. O tempo presente é referenciado pelos edifícios, que separam o "povo" da imagem da Princesa. Os braços erguidos com punhos cerrados de dois personagens indicam luta. Pela liberdade. Qual liberdade?

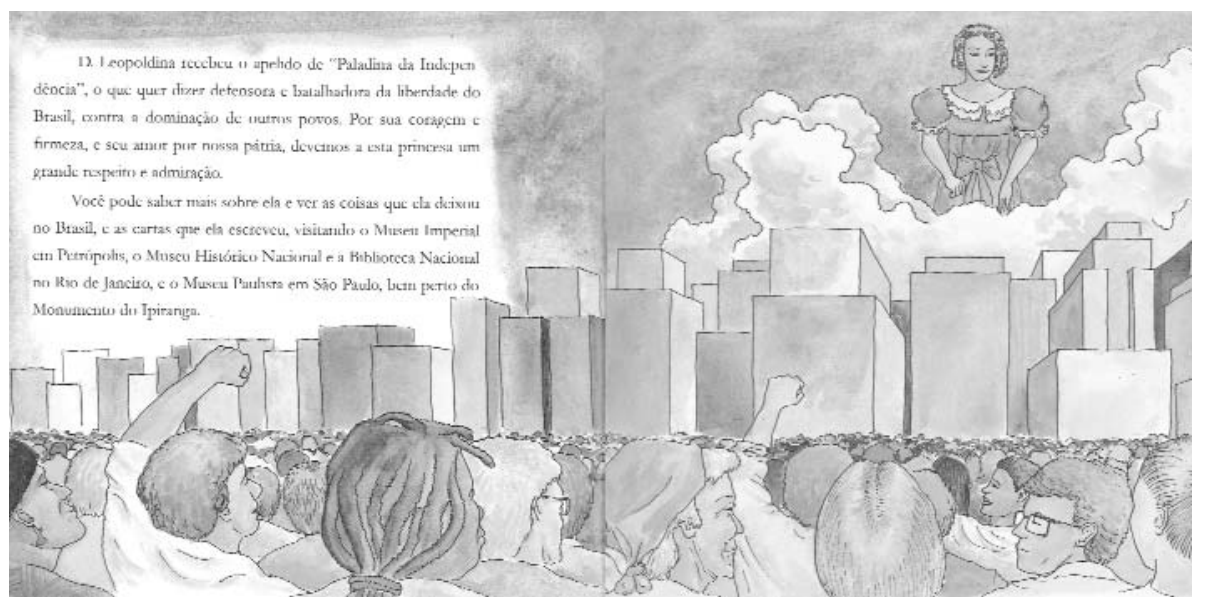

IMAGEM 2

ILUSTRAÇÃO 2 Imagem final do livro Uma princesa de fibra... A imperatriz Carolina Josefa Leopoldina, produzido pelo Museu Imperial, em 1997.

A segunda obra produzida pelo Museu, $D$. Ratão, um rato brasileiro (1999), insere-se no Projeto D. Ratão, destinado ao público infantil. O texto é de Maria de Lourdes Horta e as ilustrações, de Cláudia Nunes. São 18 páginas compostas por textos curtos e ilustrações em preto-e-branco.

A narrativa é centrada na visita de uma família de ratos que chega ao Museu Imperial em uma liteira trazida por ratos escravos. D. Ratão decide brincar de imperador e, para isso, usa os símbolos imperiais: a coroa, o manto e o cetro. $\mathrm{O}$ episódio de destaque é a abolição da escravidão na Ratolândia, que a princesinha faz em resposta a “(...) um bando de camundonguinhos pretos (...) [que] estavam chorando e pedindo para serem libertados!".

Há dois momentos de interlocução com o leitor: na primeira página, quando ele é solicitado a preencher o nome e a data de visita ao Museu, e, na última, na qual é solicitado a ligar os pontinhos da Serpe e a responder duas questões ("Você já viu este animal? Aonde?", (sic)). Ao final, há a sugestão de atividades para a criança, como colorir os desenhos 
do livro, escrever uma aventura de D. Ratão, fazer uma música ou um palácio para ele e fazer uma coroa para si mesma.

Ambas as produções analisadas não utilizam, em sua construção textual, os princípios da educação patrimonial. As fontes são apenas ilustrações do texto, o que não permite aberturas dialógicas significativas para o leitor. A despeito das profundas reavaliações historiográficas das últimas décadas, o museu reitera a interpretação dos 'fatos' como resultantes de ações individuais, que não permitem compreender os cenários, nem os processos de mudança e permanência. Neste sentido, a proposta da autora de que os leitores se compreendam como sujeitos históricos é dificultada pela abordagem dos materiais.

Os dois textos personificam excessivamente o processo histórico. O primeiro mostra a Independência do Brasil como resposta de D. Pedro I a uma carta de D. Leopoldina e ao nacionalismo de ambos. "D. Ratão" encena a abolição como um evento ligado à perspicácia de uma princesinha. Em ambas as versões, "viva, viva, viva a princesinha" (HORTA, 1999, p. 17).

\subsection{Diálogos com a memória e 0 tempo}

O Museu Histórico de Santa Catarina lançou, em 2004, a revista Uma aventura no Museu!, escrita por Renato Gomes Tapado e ilustrada por Juliana Cardin. O gênero é história em quadrinhos, com quatro personagens: as crianças Paula e Beto, o Tempo e a Memória. São 22 páginas policromáticas, encartadas em capa dura que apresenta o título da revista e, atrás, os personagens.

A história conta a visita das crianças ao museu, com o objetivo de realizar uma pesquisa para a professora. A relação entre escola e museu é explicitada desde o início. Lá, são recebidas pelas estátuas-falantes do Tempo (homem) e da Memória (mulher), que orientam o diálogo e a visita. 


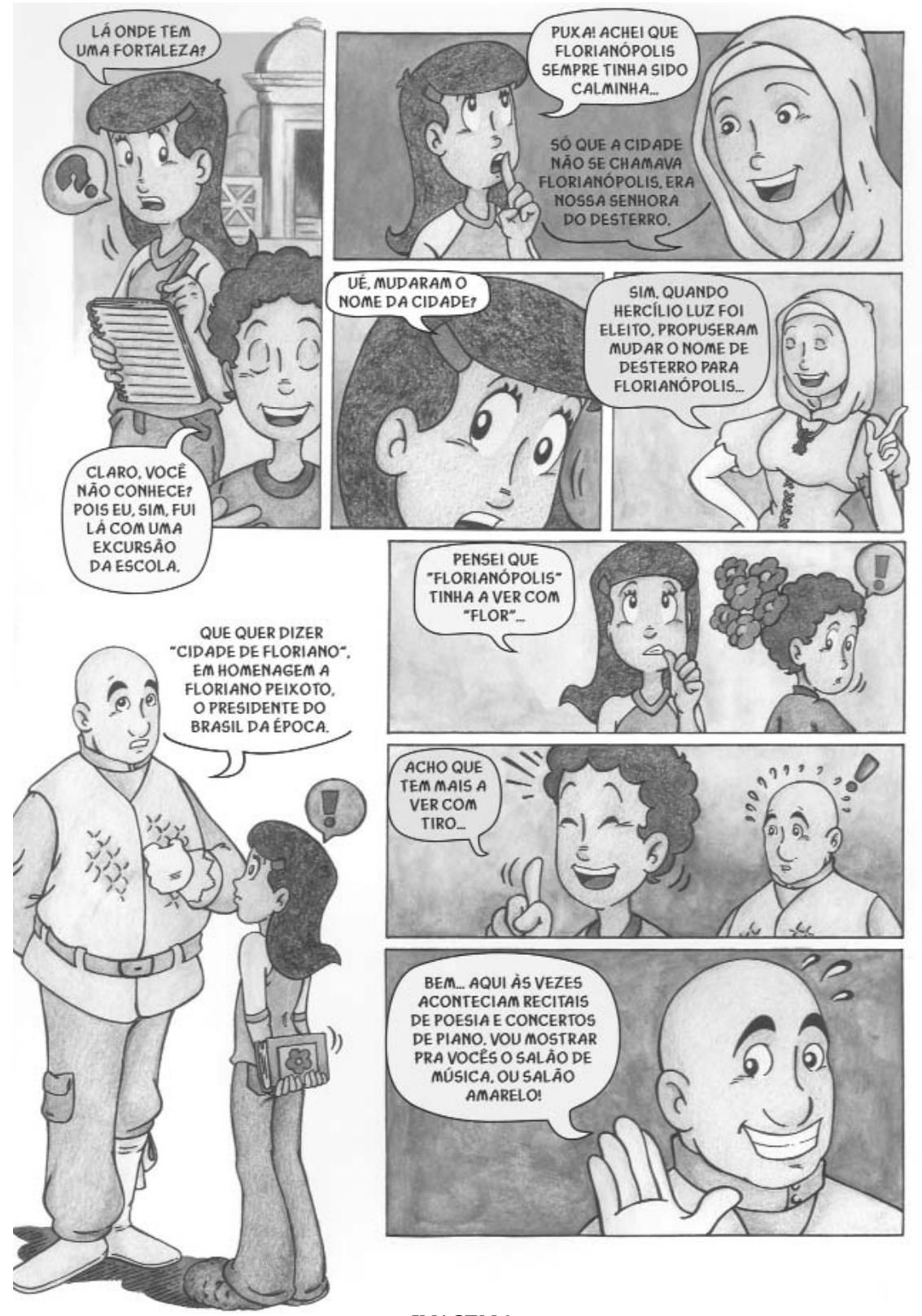

IMAGEM 3

ILUSTRAÇÃO 3 Imagem da revista Aventuras no Museu! (MHSC, 2004)

As falas do Tempo e da Memória são orientadoras da atenção das crianças, que, muitas vezes, se limitam a exprimir admiração e a perguntar dados complementares. O processo de despertar o interesse das crianças-personagens em relação ao museu é imperativo ("Prestem atenção no chão!”, “Olhem estes espelhos de cristal italiano!", "Entrem!", 
"Venham ao Salão Vermelho!", "Vejam, vou mostrar o salão azul”). É interessante observar o contraste entre o texto imperativo e as imagens dos personagens Tempo e Memória, pois, na maior parte dos quadros, eles estão sorrindo.

As fontes do museu são identificadas pelos personagens Tempo e Memória, havendo apenas demonstração de deslumbramento com o luxo e a beleza dos objetos e cômodos por parte das criançaspersonagens. Em algumas partes, Memória cita a "legenda" das obras, recriando no diálogo uma estratégia comunicativa típica da exposição. Ao abordar uma cópia do quadro "Primeira missa no Brasil", de Victor Meirelles, Paulo assusta-se com a possibilidade de o pintor copiar, ou seja, pretensamente não saber pintar algo novo. Memória não problematiza a fonte nem a relação entre a cópia-pintura. Ela diz que “(...) naquela época, isso era comum e os artistas famosos iam estudar na Europa" (MHSC, 2004, p. 11).

Episódios importantes para a história de Florianópolis são narrados, nomeados e datados, como a Revolução Federalista (1893), a Revolução de 1930 e a Novembrada. O passeio pela casa torna-se, assim, um passeio pela história de Florianópolis.

Nas últimas páginas, os personagens Tempo e Memória narram a transformação do Palácio em Museu e o processo de tombamento. $\mathrm{O}$ texto termina com um convite de visita ao museu a todos os colegas e famílias, projetando uma relação com o leitor, mesmo que implícita: "Adoramos a visita de vocês. Voltem sempre e convidem seus amiguinhos e suas familias" (MHSC, 2004, p. 21).

Os nomes Tempo e Memória parecem não ter relação com a abordagem conceitual. Não há tratamento de questões de temporalidade histórica, a não ser de referência cronológica, assim como não há nenhuma discussão sobre a memória preservada no museu ou sobre a existência de outras memórias.

O personagem Tempo censura algumas falas da Memória, como se fosse o portador da narrativa histórica do museu. Como exemplo, Memória diz às crianças, na visita ao Salão Vermelho, que "ao redor desta mesa, muitos governantes discutiram estratégias políticas. E às vezes ninguém ficava sabendo..." (MUSEU HISTÓRICO DE SANTA CATARINA, 2004, p. 11). Ao fundo do quadrinho, Paula ri com as mãos na boca e Tempo grita “Memória!", com expressão de irritação.

Beto e Paula aparecem em várias cenas com um caderninho na mão, inclusive no momento de apresentação dos personagens. Essa 
imagem reporta ao papel do visitante, no caso, um estudante, como receptor de informações que devem ser copiadas para uma pesquisa escolar.

Um formato interessante e com imenso potencial dialógico, mas que reatualiza práticas de transmissão de informações consideradas importantes para a história de uma cidade.

\subsection{0 passado como construção}

As coleções de Raymundo (MUSEUS CASTRO MAYA, s/d) é um material concebido e escrito por Vera Beatriz Junqueira e produzido pelos Museus Castro Maya (Rio de Janeiro, RJ). Não há indicação de data, mas a publicação deu-se na gestão do ministro da Cultura Francisco Weffort, durante o governo de Fernando Henrique Cardoso (1995-2003).

Trata-se de uma pasta em capa dura que abriga as fichas. A capa mostra uma montagem de fotografias pessoais do colecionador Raimundo Castro Maya e, na contracapa, há breve apresentação de sua biografia e episódios de sua vida para que as crianças os ordenem.

A atividade sinaliza para a interatividade e a criança é convidada a conhecer fatos da biografia pela ordenação temporal, o que pressupõe um trabalho de leitura. No interior da capa, a seção "as casas que viraram museus" apresenta, por meio de um texto, a transformação das casas no Museu do Açude e na Chácara do Céu. O texto aponta tanto para a temporalidade de construção das casas e seu uso original, quanto para as permanências e rupturas processadas na transformação em museus. Há uma atividade na qual a criança deve identificar as atividades realizadas em quatro espaços ${ }^{8}$, por meio da leitura da fotografia.

Há seis pranchas conceituais, sem numeração, o que permite a flexibilidade na leitura e no manuseio. Os temas das pranchas são: colecionismo, biblioteca, coleção Brasiliana, arte européia, Portinari e Debret. As pranchas são compostas por um texto informativo acompanhado por atividades variadas ligadas à apreciação estética. Há espaços próprios para o leitor escrever ou desenhar a partir das sugestões apresentadas.

O foco de todas as atividades é a expressão do leitor, encorajando-o ao uso da imaginação e da criatividade. Ao final do texto, há um quadro com conceitos relacionados ao tema e à legenda das obras (autor, obra, data, técnica e tamanho). Contudo, as fotografias pessoais não possuem legendas. Em todas as fichas há identificação da equipe envolvida na produção do material, assim como a logotipia do museu. 
Uma prancha, diferenciada por tamanho, gramatura e cor (pretoe-branco), narra a história da Chácara do Céu e pergunta ao leitor qual obra mais chamou sua atenção e por quê. Solicita-lhe ainda que elabore um desenho sobre ela no verso.

Os textos são estruturados de forma a contextualizar e problematizar os conceitos, com uma preocupação em pensar a formação do colecionador, da coleção, do acervo e dos museus. Explicita também as seleções realizadas pelo mercado da arte, pelos colecionadores e pelos museus.

É interessante a abordagem sobre a educação do olhar. O leitor é convidado a comparar, detalhar, narrar e perceber a construção mesma da fonte. As mudanças nas formas de registro também são apontadas, o que propicia a desnaturalização das imagens.

$\mathrm{Na}$ abordagem da obra de arte, o trabalho com a autoria e a imaginação leva o leitor a refletir sobre diferentes pontos de vista. Após propor várias questões sobre a leitura do quadro "A dança", de Pablo Picasso, a autora afirma: "Nenhuma dessas perguntas possui uma resposta só. Cada um de nós irá responder de uma maneira. E não há certo ou errado" (MUSEU CASTRO MAYA, s/d).

A seguir, uma prancha para análise: 

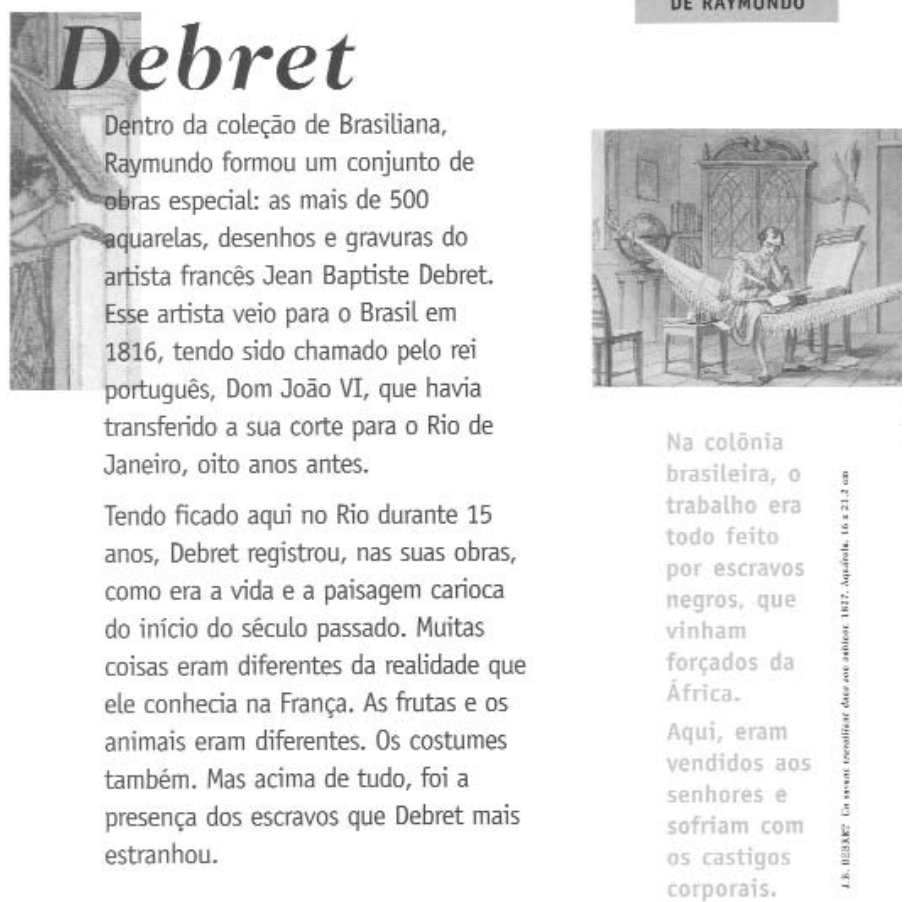

Aquarela . Jean Baptiste. Debret . Gravura . Côrte . D. Joào VI . Brasil colônia.

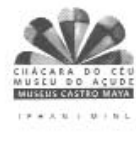

IMAGEM 4 -DEBRET

ILUSTRAÇÃO 4 - Imagem do material pedagógico As coleções de Raymundo (MUSEU CASTRO MAYA, s/d)

Como se pode verificar, há preocupação em contextualizar o artista na coleção Castro Maya e em seu tempo de produção. Da mesma forma, o trânsito das obras até o museu também é apresentado ao leitor. Após o texto, há a proposição de uma atividade de desenho ou escrita, relacionada à curiosidade ou à diferença percebida pelo leitor no museu ou nos jardins.

Provoca-se, também, o movimento conceitual de Debret em relação à escravidão, do olhar do estrangeiro em relação aos trópicos. $\mathrm{O}$ leitor é convidado ao estranhamento, o que pode fomentar a percepção de outras temporalidades e de outras culturas. 
Nessa proposta, o conceito de museu é a linha mestra dos textos e das imagens, que se articulam e dialogam entre si e com o leitor. As múltiplas temporalidades da casa são explicitadas, possibilitando a compreensão do processo de se tornar museu. O leitor participa, literalmente, da escrita do material pedagógico e as múltiplas interpretações sobre as fontes são acolhidas e incentivadas.

\section{DESAFIOS PARA A ESCRITA DA HISTÓRIA NOS MUSEUS}

É possível perceber, pela breve análise desses materiais, a existência de uma preocupação das instituições museológicas com sua função educativa. Embora seja necessário analisá-los a partir de contextos específicos de produção e difusão, podem ser ponto de partida para a percepção de concepções de história, memória e aprendizagem instrumentalizadas pelos museus históricos com o objetivo de educar.

Todos os materiais têm preocupação com a atratividade. Porém, o objetivo da maior parte parece ser informar. A didatização ocorre apenas em relação à linguagem. A narrativa preocupa-se com o fornecimento de dados, fatos e conceitos estruturados em linguagem atraente. As atividades, quando existentes, são centradas na repetição e o leitor aparece como reprodutor das falas de outrem.

Com certeza, muitos materiais interessantes ficaram de fora desta seleção. Porém, é fundamental ressaltar que todas essas iniciativas foram e são um grande avanço no campo da educação, evidenciando o quanto os museus brasileiros despertaram e estão atentos a essa problemática. Essa pequena amostra, proveniente de importantes instituições museológicas brasileiras, reforça a compreensão da necessidade de construção de elos mais significativos entre a produção pedagógica a partir dos museus e fora deles.

O autor Fernando Catroga conduz a uma reflexão importante ao analisar a relação dialética entre memória e história. De acordo com o autor, uma produz a outra, não há hierarquia. Ambas operam com a seletividade, a verossimilhança, a representação e a tridimensionalidade do tempo, ou seja, com a inclusão do projeto de futuro.

Porém, o compromisso da crítica é próprio do método histórico, que busca o cotejamento de diferentes pontos de vista; a contextualização dos enunciados e a decónpage das temporalidades. Essa reflexão conduz a pensar sobre a importância dos discursos históricos em museus exporem seus métodos de operação, assim como não abandonarem a premissa da distância temporal em relação ao passado. Da mesma forma, os 
materiais pedagógicos podem e devem explorar os potenciais da leitura do objeto, assim como o processo de construção das obras, das coleções, do museu e de suas exposições.

As pesquisas sobre ensino de História, fortalecidas a partir dos anos 1980, incorporam algumas dessas discussões para analisar os caminhos da história ensinada no Brasil. As críticas voltam-se, sobretudo, à concepção da História como algo do passado, que concilia uma concepção de ensino-aprendizagem objetivista. A primazia dos conteúdos factuais e conceituais fomenta a idéia de um conhecimento pronto, modificado tão somente no aspecto quantitativo. Nessa perspectiva, a dimensão do cotidiano e da realidade imediata dos sujeitos envolvidos na ação educativa é preterida. O olhar sobre os processos de aprendizagem estabelecidos a partir de lugares de memória, tais como museus, permite-nos aprofundar algumas questões, a exemplo da relação entre experiências culturais prévias, expectativas da visitação e resultados de aprendizagem.

Diante dessas reflexões, professores e pesquisadores da História vêm apontando alternativas metodológicas para a consolidação do ensino formativo, centrado na aprendizagem. Se pensarmos a aprendizagem como processo cognitivo marcado por leituras de mundo particulares que se colocam em confronto ou interação no espaço escolar, percebemos a necessidade do diálogo entre os sujeitos, no sentido de promover o movimento conceitual inerente ao estudo da História.

A ação pedagógica incide sobre conhecimentos prévios diferenciados, resultantes de trajetórias e inserções sociais específicas, mediados, entretanto, por discursos produzidos por instâncias tais como a mídia, lugares de memória e a própria formação escolar. O diálogo permite a criação de vínculos significativos entre os conhecimentos prévios e as novas informações, possibilitando a construção de uma aprendizagem histórica significativa que ultrapasse a mera memorização. O diálogo envolve a interação entre os sujeitos na aproximação do objeto a ser conhecido. Paulo Freire assinala que

(...) o diálogo é a confirmação conjunta do professor e dos alunos no ato comum de conhecer e re-conhecer o objeto de estudo. Então, em vez de transferir o conhecimento estaticamente, como se fosse uma posse fixa do professor, o diálogo requer uma aproximação dinâmica na direção do objeto. (FREIRE, 2001, p. 123).

Por outro lado, Margarida Louro Felgueiras (1994) destaca, em sua proposta metodológica sobre o ensino de História, que é na dimensão epistemológica do conhecimento histórico que devem ser buscadas as 
principais aproximações com o saber histórico. $\mathrm{O}$ ofício do historiador e seus instrumentos de trabalho lançariam pontes para a compreensão da história ensinada em museus.

O conhecimento histórico se dá a partir de vestígios. O historiador, no entanto, não se conforma com a simples ordenação das fontes; é preciso saber interrogar os documentos, a partir de suas hipóteses. De acordo com E. P. Thompson (1981, p. 38), "a evidência histórica existe, em sua forma primária, não para revelar seu próprio significado, mas para ser interrogada por mentes treinadas numa disciplina de desconfiança atenta”.

É necessária ainda a compreensão da fonte em sua dimensão social e histórica, refletindo sobre os sentidos de sua conservação, sua organização e seu pertencimento à instituição. No caso do museu, é preciso pensar a história das fontes, ou seja, os caminhos de seleção, aquisição, doação, preservação e exposição a que estão sujeitas. Neste sentido, o material produzido pelos Museus Castro Maya apontam ao leitor a formação da coleção e as seleções efetuadas pelo colecionador, em seu tempo.

Marc Bloch, em seu livro sobre o ofício do historiador, propõe a promoção de uma educação da sensibilidade histórica, em relação estrita com os pressupostos que defende para a construção do conhecimento histórico. De acordo com Sonia Miranda (2004), é possível indicar tendências, a partir do conjunto da obra de Bloch, sobre o que seria o seu apêndice sobre Ensino de História, nunca concluído. Segundo a autora,

um ensino capaz de formar, pelo entusiasmo, novos historiadores, porém, ao mesmo tempo, capaz de fornecer utensílios mentais que permitam a qualquer indivíduo acumular condições de conhecer o presente e, desse ponto de vista, olhar o passado, interpretando-o e buscando regularidades por intermédio de procedimentos comparativos. Um ensino que permitisse ao sujeito lançar mão, em sua vida cotidiana, daquilo que envolve a forma de investigação da História para se posicionar perante os fatos, tendo em vista o que isso representa em termos de possibilitar a condição de olhar sob múltiplos ângulos, e argumentar, com rigor, mas sem deixar de considerar que a percepção da diversidade precisa se sobrepor sempre à busca " $d a$ " verdade. (MIRANDA, 2004, p. 41)

Essas discussões investem de importância o pensar sobre a ação educativa a partir de museus. A compreensão e o desenvolvimento de procedimentos teórico-metodológicos contribuem para a formação de novos olhares sobre o museu, desafiando o discurso monológico da exposição permanente, o que pode ser potencializado pelos materiais educativos. 
$\mathrm{Na}$ medida em que as crianças entrem em contato com as estratégias de linguagem e produção do discurso museológico, seus olhares sobre eles tendem a mudar de forma significativa. Da mesma forma, a compreensão dos métodos do historiador no manejo das fontes históricas estimula a curiosidade e a atração pelos processos de construção de conhecimento. Assim, novos leitores de mundo poderão, posteriormente, criar seus próprios discursos.

Nas discussões e propostas a respeito das políticas de memória nos museus, o poder discursivo deles é exacerbado tanto na perspectiva de refletir os processos ideológicos envolvidos na definição do passado a ser visto e celebrado quanto na redenção provocada pela inserção de memórias e ressentimentos de grupos alijados da produção de sua escrita.

No entanto, a questão da recepção dos museus é fundamental para a percepção da historicidade dos diálogos projetados pelos discursos museológicos e para a compreensão dos processos de apropriação que ensejam.

Por outro lado, em um cenário marcado pela pauperização e/ou pelo isolamento político dos setores educativos dos museus, a tarefa de construir materiais, que envolve a reflexidade sobre as práticas, a sondagem de estratégias pedagógicas, os recursos para produção material, entre outros, é um desafio diuturno. É necessário também discutir a resistência em mudar o discurso dos museus históricos, cuja grafia é perpetuada nas memórias infantis, nas visitas escolares e nos momentos celebrativos.

Myriam Sepúlveda destaca que "os museus têm a função de legitimar um imaginário junto ao público e, quando cumprem sua função, não conseguem modificar este imaginário com facilidade" (SANTOS, 2006, p. 56). No caso dos museus históricos, tal tarefa é ainda mais espinhosa e é preciso refletir sobre as expectativas do público em relação a eles, assim como os processos de reconhecimento.

Em um momento em que as políticas públicas nacionais incentivam o papel dos museus como agentes de democratização e de valorização das culturas, em que os discursos sociais apontam para o papel de resgate do passado, em que as escolas saúdam o dever de memória, os museus históricos se repensam.

A par dos desafios monumentais, que incluem as pluralidades, o uso de diferenciadas linguagens, a consolidação da acessibilidade física e cultural, os museus históricos precisam dialogar com a própria construção do conhecimento histórico. 
Conforme aponta Nestor Canclini (1994), é necessário construir caminhos para a co-participação e estudar amplamente preferências, conhecimentos prévios e expectativas do público. Ainda, há a necessidade imperiosa de partilhar a própria construção do conhecimento museal e, nesse sentido, dividir com o público as dificuldades da arqueologia ou da história, a luta dos pesquisadores para descobrir um sentido ainda seguro, pode ser uma técnica legítima para suscitar a curiosidade e atração pelo conhecimento. A incerteza é também a ocasião para que resplandeça o que uma máscara ou uma vasilha acolhem de mistério e poesia. (CANCLINI, 1994, p. 113)

Ao explorar seu processo de construção de memórias, o museu histórico pode ensejar a apropriação da linguagem e da ferramenta pelos diferentes grupos sociais, fomentando o diálogo, e não apenas o reconhecimento. Jesus Barbero (1999) propõe o museu como espaço de choque e negociação cultural, de articulação entre a imagem e a ausência. A dimensão dialógica propicia aos museus e às suas ações educativas densidade para discutir o pluralismo e o processo litigioso das memórias. É necessário prever, incluir e expor formas diferentes de perceber o tempo e a história. É possível recuperar os "futuros olvidados" e escapar do fatalismo que o presente projeta em relação ao futuro.

\section{CONSIDERAÇÕES FINAIS}

Memória e História aparecem na mitologia grega como mãe e filha, Mnemósime e Clio. No processo de construção do pensamento ocidental a respeito do passado e, portanto, de formas de registrá-lo, preservá-lo, acessá-lo e difundi-lo, "memória" e "história" foram postas em lados opostos da balança.

As propostas de criação e 'modelagem' de uma consciência histórica nacional ensejaram, no século XIX, o surgimento e/ou o fortalecimento de instituições dedicadas ao ensino da História, concebida como magistrae vita. Clio, como toda musa, foi reverenciada em seus templos: a escola, o museu, o arquivo e a biblioteca. Ensinar História envolvia a transmissão dos ensinamentos sobre a linearidade do tempo, a espacialidade de um país e a identidade de uma nação.

Porém, há tempos, o alicerce dessa concepção foi abalado com a entrada ruidosa de personagens não previstos na trama inicial. Os museus, em especial, foram sacudidos por demandas identitárias de variados grupos, que reivindicaram o direito à memória.

É necessário, assim, pensar o museu, o "templo das musas", e suas propostas de construção de sentidos do passado a partir da 
densidade de conflitos e das descontinuidades. Em outro momento, apenas a entrada para o banquete de Clio seria comemorada. Contudo, o desafio não é mais substituir personagens, datas e marcos e, sim, redefinir radicalmente a concepção antiquária dos museus, centrada na busca de essências culturais, na difusão vertical do conhecimento e na ritualização do passado. Compreende-se que é preciso manejar suas ferramentas e seus espaços ${ }^{10}$. E, não menos importante, garantir a renovação dos olhares do público.

Novas questões assolam a relação entre mãe e filha mitológicas. Ao longo do último século, ambas se modificaram em essência e o diálogo necessita de novas referências de linguagem. É possível afirmar que o final do século passado marca a entronização da memória, que, soberana, oblitera as conquistas de sua filha mediante a promessa de que todos os seus súditos possam partilhar de seu reinado. Porém, Clio não é mais a mesma.

Huyssen (2000) alerta para a eficácia do monumento em produzir esquecimento. Que os museus históricos consigam abrir suas portas. Expor não apenas o discurso, mas também seu processo de construção. Pensar e fazer pensar sobre coleções, seleções e interpretações. Sobre os fios de lembrança e as tramas de esquecimento.

\section{REFERÊNCIAS}

ABREU, Regina. A fabricação do imortal: memória, história e estratégias de consagração no Brasil. Rio de Janeiro: Rocco: Lapa, 1996.

ALENCAR, Vera Maria Abreu de. Museu-educação: se faz caminho ao andar... 1987. Dissertação (Mestrado em Educação). Pontifícia Universidade Católica do Rio de Janeiro, Rio de Janeiro, 1987.

ANICO, Marta. A pós-modernização da cultura: patrimônio e museus na contemporaneidade. Horizontes Antropológicos, Porto Alegre, ano 11, n. 23, p. 71-86, jan./jun. 2005.

BAKHTIN, Mikhail (1929). Estética da criação verbal. 4 ed. São Paulo: Martins Fontes, 2003.

BAKHTIN, Mikhail. Marxismo e filosofia da linguagem. 11 ed. São Paulo: Hucitec, 2004.

BAKHTIN, Mikhail; VOLOSHINOV, V. N. Discurso na vida e discurso na arte (sobre poética sociológica). Trad. Cristóvão Tezza para uso didático. 1926.

BARBERO, Jesus-Martin. Cambios en la percepción de la temporalidad. In: MINISTÉRIO DA CULTURA. Museo y memória nacional. Colômbia, 1999.

BATISTA, Antônio Augusto Gomes. Um objeto variável e instável: textos, impressos e livros didáticos. In: ABREU, Márcia (Org). Leitura, história e bistória da leitura. São Paulo: Mercado de Letras, 2002.

BREFE, Ana Claudia Fonseca. O Museu Paulista: Affonso de Taunay e a memória nacional. São Paulo: Editora Unesp, 2005.

CANCLINI, Néstor García. O Patrimônio cultural e a construção imaginária do 
nacional. Revista Patrimônio Histórico e Artístico Nacional. n. 23, 1994.

CATROGA, Fernando. Memória, história e historiografia. Coimbra: Quarteto Edições, 2001. CHAGAS, Mário. Memória e poder: focalizando as instituições museais. Interseções.. Rio de Janeiro, UERJ, ano 3, n. 2, p.5-23. jul./dez. 2001.

FARACO, Carlos Alberto (Org). Diálogos com Bakhtin. Curitiba: Editora UFPR, 1996.

FARACO, Carlos Alberto. Autor e autoria. In: BRAIT, Beth. Bakthin: conceitos-chave. São Paulo: Contexto, 2005.

FELGUEIRAS, Margarida Louro. Pensar a História, repensar seu ensino. Porto: Porto Editora, 1994.

FREIRE, Paulo; SHOR, Ira. Medo e ousadia: o cotidiano do professor. 9 ed. Rio de Janeiro: Paz e Terra, 2001.

HORTA, Maria de Lourdes; GRUNBERG, Eveline; MONTEIRO. Guia básico de educação patrimonial. Petrópolis: Museu Imperial: IPHAN, 1999.

HORTA, Maria de Lourdes. D. Ratão I: um rato brasileiro. Petrópolis: Museu Imperial: IPHAN: MINC, 1999.

HORTA, Maria de Lourdes. Uma princesa de fibra... a Imperatriz Carolina Josefa Leopoldina. Petrópolis: Museu Imperial, 1997.

HUYSSEN, Andreas. Seduzidos pela memória. Rio de Janeiro: Aeroplano, 2000.

MIRANDA, Sonia Regina. Sob o signo da Memória: o conhecimento histórico dos professores das séries iniciais. 2004. Tese. (Doutorado em Educação), Campinas, Unicamp, 2004.

MUSEUS CASTRO MAYA. As colecõos de Raymundo. Rio de Janeiro: MCM; IPHAN; MINC, s/d.

MUSEU HISTÓRICO DE SANTA CATARINA. Uma aventura no museu! Florianópolis: MHSC, 2004.

PIO, Leopoldo Guilherme. Musealização e cultura contemporânea. Musas: Revista Brasileira de Museus e Museologia, Rio de Janeiro, ano 2 n. 2, p. 48-57, IPHAN, 2006.

RICOUER, Paul. La mémoire, l'bistoire, l'oubli. Paris: Seuil, 2000.

THOMPSON, E. P. A miséria da teoria. Rio de Janeiro: Zahar, 1981.

SANTOS, Myriam Sepúlveda dos Santos. A escrita do passado em museus históricos. Rio de Janeiro: Garamond, 2006.

\section{NOTAS}

${ }^{1}$ Utilizaremos a denominação tradicional, apesar de concordarmos com a afirmativa de Mário Chagas para quem, no limite, todos os museus são históricos, artísticos e científicos.

${ }^{2}$ Jogos de palavra-cruzada, moldes para colorir, sugestão de brincadeira com massinhas, jogos de quebra-cabeça e montagem de bonecas de papel e colagens. Por vezes, apenas o tema possui relação com o museu e nenhuma reflexão é desenvolvida sobre as noções de objeto, coleções e exposições, por exemplo.

${ }^{3}$ Caixas com objetos variados, varais de leitura, linha do tempo, fotografias, dioramas, etc.

${ }^{4}$ Os materiais propostos para os professores parecem ser objeto de maior preocupação dos museus, possivelmente pela sua ação disseminadora. Apesar do potencial de análise das fontes, foram selecionadas as enunciações destinadas à fruição dos próprios leitores, e não à formação dos mediadores. 
${ }^{5}$ A ficha está reproduzida no anexo da Dissertação de Mestrado em Educação de Vera Alencar, intitulada Museu-educação: se faz caminho ao andar... (Rio de Janeiro, 1987).

${ }^{6}$ A experiência pedagógica do Museu Imperial ensejou a produção de, ao menos, três dissertações acadêmicas com o objetivo de avaliar experiências museológicas lá desenvolvidas, como a organização da exposição permanente, o uso de folhas didáticas e a atividade "D. Ratão", destinadas às crianças. Todas foram defendidas no Mestrado em Educação da Pontifícia Universidade Católica do Rio de Janeiro: "Museu-educação: se faz cami-nho ao andar" (1986), de Vera de Alencar; "Uma casa exemplar. Pedagogia, memória e identidade no Museu Imperial de Petrópolis" (1994), de Alda Heizer; e, por fim, "Lições das coisas (ou canteiro de obras) através de uma metodologia baseada na educação patrimonial” (1997), de Magaly Cabral.

7 "Desembarque de D. Leopoldina", de Jean Baptiste Debret (s/d) e "Proclamação da Independência”, de François René Moreaux (1844).

${ }^{8}$ Os espaços são: um dormitório, uma sala, uma biblioteca e uma cozinha.

${ }^{9}$ Expressão utilizada por Jésus Barbero (1999), ao discutir a noção de temporalidade de Walter Benjamin, que destaca a abertura do passado em relação às potencialidades não realizadas. Segundo o autor, "hay un futuro olvidado en el pasado que es necesario rescatar, redimir y movilizar” (BARBERO, 1999, p.53).

${ }^{10}$ Mário Chagas propõe a idéia de museu como lápis, uma ferramenta que exige aprendizado da técnica de manipulação e um processo de alfabetização. Com esta rica metáfora, também é factível pensar a necessidade das escritas se transformaram em livros, ou seja, encontrarem condições de produção para sua ampla circulação e fruição.

Recebido: $10 / 03 / 08$

Aprovado: 11/04/08

Contato:

Rua José Ludolf de Melo, 26

Granjas do Bosque

Juiz de Fora - MG

BRASIL

CEP: 36033-570

E-mail:mardilha@terra.com.br 